\title{
The Effect of Positive Psychology Education on Improving the Psychological Resilience of Postgraduates
}

\author{
Yong Gao ${ }^{1, *}$
}

${ }^{1}$ Guangdong Mechanical \& Electrical Polytechnic, Guangzhou, Guangdong, China

*Corresponding author. Email: girlmaomi@163.com

\begin{abstract}
In recent years, tragedies of college graduate students caused by psychological issues have occurred frequently. This paper mainly studies the effect of positive psychology on improving psychological resilience of postgraduates and enhancing their psychological well-being. Objective: It aims to explore the effect of positive psychology education on improving psychological resilience of postgraduates. Methods: 104 postgraduates of a university in Guangdong province were investigated by questionnaire. Psychological resilience scale, Campbell well-being index scale and adolescent life events scale were used to accomplish the test. Results: The results show that the psychological resilience of postgraduates after the course was significantly improved, and the differences in self-acceptance, emotional stability and problem solving before and after the course were statistically significant $(P<0.05)$. Their happiness index after the course $(\mathbf{1 2 . 4 8} \pm \mathbf{0 . 2 7})$ was significantly higher than that before the course $(\mathbf{1 0 . 9 6} \pm 0.34)$ $(P<0.001)$. Students' life events in interpersonal relationship and health adjustment after the course were significantly lower than those before the course $(\mathbf{P}<\mathbf{0 . 0 5})$. Conclusion: It can be concluded that positive psychology can significantly improve postgraduates' psychological resilience, happiness index and reduce the occurrence of life events.
\end{abstract}

Keywords: postgraduates, psychological resilience, positive psychology

\section{INTRODUCTION}

Positive psychology is a kind of psychology developed by American psychologist Seligman at the end of 20th century. Positive psychology focuses on positive information about people, such as optimism, love, tolerance and other qualities, and is a discipline that focuses more on the positive side. This discipline can not only cure mental illness, but also discover and cultivate outstanding talents.

The research on psychological resilience has become a hot topic in psychology. It refers to the good adaptation of individuals in the face of great pressure in life. People with good psychological resilience can make use of their positive psychology, acquire good adaptability, and maintain their development in adversity [1]. The research scope of psychological resilience has been wide in China, focusing on whether individuals can effectively cope with various stress situations. For example, Xu Xianming and Qian Sheng et al. studied the protective mechanism of psychological resilience on the tendency to conduct problems of leftbehind children [2]. Li Ying studied the relationship between high school students' psychological resilience and learning burnout [3]. From the perspective of positive psychological education, this study explores the role of positive education in improving psychological resilience and daily learning effect of postgraduates.

\section{RESEARCH PROCESS}

\section{A. Object of study}

A total of 104 postgraduates in a university in Guangzhou, Guangdong province, were surveyed by questionnaire.

\section{B. Methodology}

1) Psychological resilience: College students' psychological resilience scale was adopted [2]. The scale adopted a five-level scoring method, with 1 representing "complete non-conformity" and 5 representing "complete conformity", including a total of 32 questions. There are six dimensions in the scale: a. friend support, b. family support, c. self-efficacy, d. emotional stability, e. problem solving, f. selfacceptance. A higher score indicates higher level of psychological resilience.

2) Happiness index: Campbell happiness index scale was adopted [4]. The scale consists of two parts: 
life satisfaction questionnaire and overall emotion index scale.

The overall emotion index scale is composed of 8 items. It adopts the seven-level scoring method to represent being completely happy or satisfied, with 7 representing very unhappy or dissatisfied. All the questions were scored in reverse, ranging from the least happy to the happiest on a scale of 2.1 to 14.7 .

3) Life events: Adolescent life events scale was adopted [5]. The scale consists of 27 questions and has 6 dimensions: a. interpersonal relationship, b. learning pressure, c. punishment, d. loss, e. healthy adjustment, f. others. Psychological feelings were rated in five levels, namely no effect (1), mild (2), moderate (3), severe (4) or extremely severe (5). The higher the score is, the more serious the event is.
4) Data collection and statistics: SPSS13.0 was used for data processing. Paired sample t test was used to compare the differences of psychological resilience, happiness index and life events. $\mathrm{P}<0.05$ was considered statistically significant.

\section{RESEARCH RESULTS}

\section{A. General situation}

The general situation of psychological resilience of postgraduates is shown in "Table I", which shows the psychological resilience of postgraduates after the course is significantly improved. The differences in self-acceptance, emotional stability and problem solving before and after the course were statistically significant $(\mathrm{P}<0.05)$.

TABLE I. THE EFFECT OF PSYCHOLOGICAL RESILIENCE BEFORE AND AFTER THE COURSE

\begin{tabular}{clll}
\hline psychological resilience & before the course & after the course & P value \\
\hline self-efficacy & $3.52 \pm 0.46$ & $3.66 \pm 0.41$ & 0.112 \\
self-acceptance & $3.44 \pm 0.51$ & $3.79 \pm 0.47$ & 0.001 \\
emotionormal & $3.31 \pm 0.44$ & $3.56 \pm 0.69$ & 0.024 \\
problem solving & $3.27 \pm 0.74$ & $3.72 \pm 0.47$ & 0.001 \\
friend support & $3.59 \pm 0.50$ & $3.74 \pm 0.46$ & 0.078 \\
family support & $3.59 \pm 0.52$ & $3.75 \pm 0.48$ & 0.156 \\
\hline
\end{tabular}

\section{B. Happiness index}

The happiness index after the course $(12.48 \pm 0.27)$ was significantly higher than that before the course $(10.96 \pm 0.34)(\mathrm{P}<0.001)$, as can be seen in "Fig. 1".

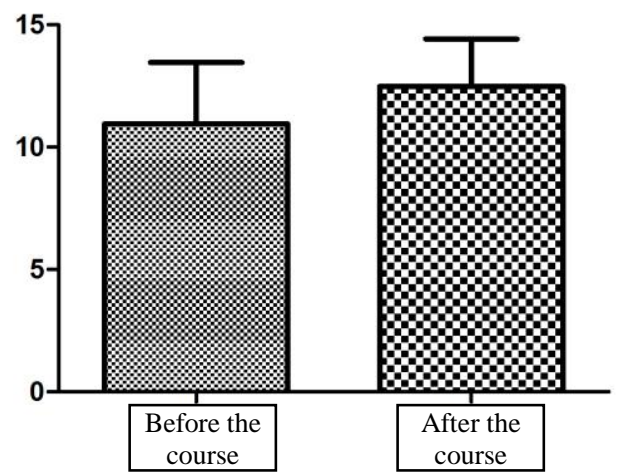

Fig. 1. The happiness index before and after the course.

\section{Life events}

After the course, students' life events in interpersonal relationship and healthy adaptation were significantly lower than that before the course $(\mathrm{P}<0.05)$. However, although their learning pressure, punishment and loss decreased, the difference was not significant (P>0.05), as can be seen in "Table II".

TABLE II. THE OCCURRENCE OF LIFE EVENTS BEFORE AND AFTER THE COURSE

\begin{tabular}{clll}
\hline life events & before the course & after the course & P value \\
\hline interpersonal relationship & $1.81 \pm 0.11$ & $1.60 \pm 0.10$ & 0.001 \\
learning stress & $1.94 \pm 0.11$ & $1.77 \pm 0.12$ & 0.060 \\
punishment & $0.29 \pm 0.09$ & $0.19 \pm 0.06$ & 0.058 \\
loss & $0.35 \pm 0.10$ & $0.40 \pm 0.11$ & 0.322 \\
Health adaptation & $1.48 \pm 0.12$ & $1.17 \pm 0.11$ & 0.022 \\
others & $0.19 \pm 0.08$ & $0.12 \pm 0.05$ & 0.103
\end{tabular}




\section{DISCUSSION AND REFLECTION BASED ON RESULTS}

American psychologist Seligman believes that the main task of psychology is the treatment of psychosomatic diseases, enhancement of happiness and cultivation of talents [6]. For a long time, psychology mainly focuses on the negative psychological problems for a variety of research. However, with the development of the society, "positive psychology" has been paid more and more attention by psychologists in China and abroad. Snyder and Lopez edited the "Handbook of Positive Psychology in Schools" [7], which formally established the positive psychology as a separate discipline. According to professor Seligman, positive psychology is based on the advantages and noble morality of human beings and studies various psychological phenomena with a positive attitude. It then stimulates the research object's positive thoughts, help the human to better tap their own potential and develop good character. Johann Friedrich Herbart, a famous educator, believed that "pedagogy should be based on psychology and ethics. Psychology can provide specific methods and means for education." This study mainly evaluated the role of the positive psychology education in graduate education by analyzing the psychological tests before and after graduate students received the course.

Harvard's course in positive psychology has also become a miracle of the university's curriculum, attenders of which briefly topping the classes. Professor Tal Ben Shahar, who teaches the course, develops it by teaching students what happiness is and how to pursue it. More than 200 universities in the United States offer courses in positive psychology, and almost all of them are the most attended or among them. More and more institutions, organizations and consulting firms are offering the course in the United States, some of which are even world-renowned consulting firms. Why is there special interest in this new field from all walks of life in all countries? Because it works, it really does. Therefore, colleges and universities should change the previous traditional psychology education model, so that students can gradually master the methods to obtain happiness in practice [8].

The results of this study show that the psychological resilience of postgraduates is at a medium level, and the psychological resilience of some postgraduates is lower than that of a low level, which is consistent with the study of Wen Ya et al. [9]. In recent years, various extreme events of graduate students have been reported frequently, which are often related to their psychological vulnerability of students, and should be paid much attention to by teachers [10]. The main purpose of traditional mental health education is to alleviate or eliminate psychological problems. A mental health course is a course that asks students to identify various psychological problems. It is necessary to identify and intervene in students with mental health problems, and strengthen the care, support and guidance for these students in the process of their study and life [9]. But with the increasing number of students' psychological problems, a new and more practical method is urgently needed. Positive psychology, on the other hand, enables students to focus more on their positive side and make themselves and those around them happier. The results of this study also found that this method has a high practicability. After the positive psychology course, the students' psychological resilience level increased significantly, especially in the aspects of self-acceptance, emotional stability and problem solving. As a result, graduate students can benefit greatly from positive psychology.

Positive emotions can improve not only subjective well-being and mental health, but also physical health, as well as prevent and rehabilitate diseases [11]. This study also found that students who studied positive psychology before the study received significantly fewer life events related to health adjustment. The results confirm once again the role of positive psychology in physical health. This study found that the time for students to encounter interpersonal relationships after the course also decreased significantly, indicating that positive psychology can also improve students' interpersonal relationships.

The mental health education in colleges and universities should take it as its mission to help students to be happy and grow up healthily. At present, the counselors of various colleges and departments don't have profound understanding of positive psychology, and the method of psychological education is still to eliminate mental diseases. Therefore, colleges and universities need to organize counselors or psychological counselors to conduct training and study, so that they can master the methods of positive psychology, and then carry out positive psychology education to students. In terms of teaching methods, it is necessary to change the way of teaching in large class, conduct more small-class teaching and discussion, provide more platforms for students to interact with each other, and enhance the classroom experience, so as to improve the classroom effect. This can not only teach students the theory of positive psychology, but also train them to use the methods of positive psychology and improve their happiness index, so as to further improve educational outcomes.

\section{CONCLUSION}

As an important part of outstanding talents, it is of great significance to improve the psychological resilience of postgraduate students. Positive psychology can be used to improve the psychological resilience and 
happiness index of graduate students. Therefore, schools should carry out various activities to strengthen the education of positive psychology.

\section{References}

[1] Shen Liemin. A Preliminary Probe Into the Resilience of Students With Learning Disabilities [J]. Psychological Science. 2009, 32 (3): 703-705. (in Chinese)

[2] Xu Xianming, Qian Sheng. The Protective Mechanism of Psychological Resilience on the Disposition of Left-behind Children [J]. Chinese Journal of Special Education. 2012 (3): 68-72. (in Chinese)

[3] Li Ying. Research on the Relationship Between Psychological Resilience and Learning Burnout in High School Students [J]. Legal System and Society. 2015 (1): 223-225. (in Chinese)

[4] Tu Cuiping, Fan Fumin, Li Songwei. Effects of Psychological Potential Training Courses on the Cultivation of Top Students: Quantitative and Qualitative Evidence [J]. Research On Education Tsinghua University. 2014, 35 (5): 118-124. (in Chinese)

[5] Wang Xiangdong. Handbook of Mental Health Rating Scale [M]. Chinese Mental Health Journal. 1999: 106-108. (in Chinese)

[6] Seligman MEP. Authentic happiness: using the new positive psychology to realize your potential for lasting fulfillment $[\mathrm{M}]$. New York: Free Press; 2002.

[7] Snyder CR, Lopez SJ. Handbook of positive psychology [M]. Oxford England; New York: Oxford University Press; 2002.

[8] Sun Xionghui. From the Negative to the Positive - Positive Psychology Concept of College Psychological Health Education [J]. Journal of Chongqing College of Electronic Engineering. 2010, 19 (4): 84-85. (in Chinese)

[9] Wen Ya, Liu Wei, Chen Quan. On the Relationship of Postgraduate students' Phychological Resilience and Emotional Intelligence [J]. Journal of Graduate Education. 2014 (5): 48-51. (in Chinese)

[10] Ji Yanhong. On the Relationship Between Female College Students' Resilience, Stressful Events and Social Support of Them [J]. Chinese Journal of Special Education. 2013, 2: 81-86. (in Chinese)

[11] Guo Xiaoyan, Wang Zhenhong. Concept, Function and Significance of Positive Emotion [J]. Advances in Psychological Science. 2007, 15 (5) 810-815. (in Chinese) 